\title{
Abstract
}

\section{A Review of International Teledermatology}

\author{
Karen McKoy ${ }^{1,2}$ \\ ${ }^{1}$ Lahey Hospital \& Medical Center, Burlington, MA, United States \\ ${ }^{2}$ Harvard Medical School, Harvard University, Boston, MA, United States \\ Corresponding Author: \\ Karen McKoy \\ Lahey Hospital \& Medical Center \\ 67 South Bedford Street \\ Burlington, MA, 01803 \\ United States \\ Phone: 17817448443 \\ Email: thrlmcky@gmail.com
}

\section{Abstract}

Background: The use of teledermatology has been evolving slowly for the delivery of health care to remote and underserved populations. Advancements in technology and the recent COVID-19 pandemic have hastened its use internationally.

Objective: An international survey was done to assess teledermatology use before and during the COVID-19 pandemic.

Methods: In addition to an updated literature review from 2015 to 2021, a survey instrument was formatted in Google Forms in English and distributed electronically to international personal contacts of the authors, as well as to international dermatology and teledermatology societies of members of the International League of Dermatological Societies and members of the International Society of Teledermatology. Answers from US dermatologists were excluded.

Results: 110 survey responses were received from 33 countries. Barriers to the use of teledermatology have fallen considerably in the last year.

Conclusions: Teledermatology use has increased significantly in recent years in both government-sponsored and private health care systems and individual practices. There are no recognized international practice guidelines and there is variable use within countries. Many barriers remain to increasing the use of teledermatology.

Conflicts of Interest: None declared.

(iproc 2022;8(1):e36901) doi: $10.2196 / 36901$

\section{KEYWORDS}

international; COVID-19; dermatology; teledermatology; telemedicine

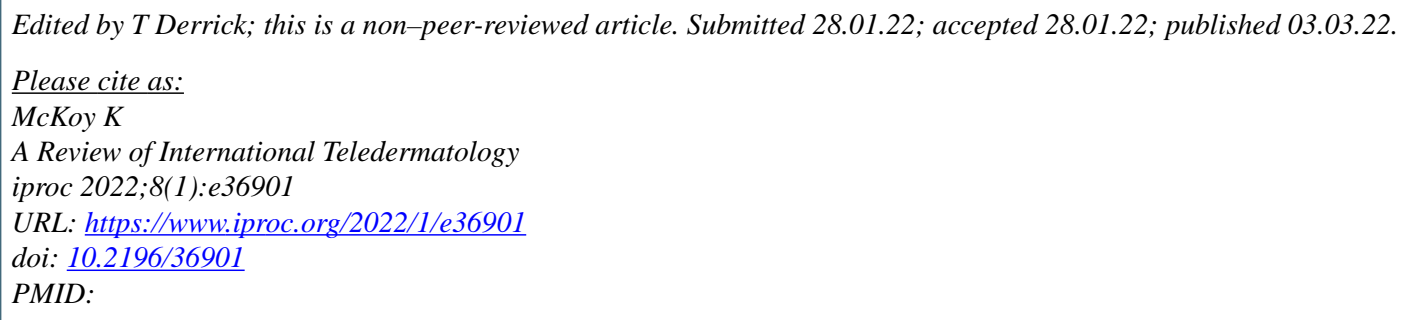

CKaren McKoy. Originally published in Iproceedings (https://www.iproc.org), 03.03.2022. This is an open-access article distributed under the terms of the Creative Commons Attribution License (https://creativecommons.org/licenses/by/4.0/), which permits unrestricted use, distribution, and reproduction in any medium, provided the original work, first published in Iproceedings, 
is properly cited. The complete bibliographic information, a link to the original publication on https://www.iproc.org/, as well as this copyright and license information must be included. 